(RESEARCH ARTICLE)

\title{
Illicit drugs in wastewater treatment plants utilization of wastewater-based epidemiology in a Brazilian regional city
}

\author{
Ferreira Aldo Pacheco * \\ Oswaldo Cruz Foundation, Sergio Arouca National School of Public Health, Brazil. \\ Publication history: Received on 18 March 2020; revised on 29 March 2020; accepted on 30 March 2020
}

Article DOI: https://doi.org/10.30574/wjarr.2020.6.1.0069

\begin{abstract}
Illicit drugs, belonging to a category of contaminants of growing and threatening concern, must be taken into account in environmental management due to their social and public health risks. Wastewater-based epidemiology consists in acquiring relevant information about the lifestyle and health status of the population through the analysis of wastewater samples collected at the influent of a wastewater treatment plant (WWTP). This method has been applied to the analysis of influent samples from 4 WWTPs located in Rio de Janeiro Municipality, Brazil, in order to investigate the presence of illicit drugs and their metabolites. These included cocaine (COC), benzoylecgonine (BE, cocaine metabolite), amphetamine (AMP), methamphetamine (METH), and 11-nor-9-carboxy-tetrahydrocannabinol (THC-COOH, THC metabolite). Concentrations of COC and its main metabolite BE ranged from 201.3 to $2751.5 \mathrm{ng} / \mathrm{L}$ and from 630.7 to $5849.2 \mathrm{ng} / \mathrm{L}$, respectively. Amphetamine-like stimulants ranged from 1.7 to $110.0 \mathrm{ng} / \mathrm{L}$ for AMP, and from 55.3 ng/L to $477.4 \mathrm{ng} / \mathrm{L}$ for METH. THC-COOH ranged from 188.8 to $940.2 \mathrm{ng} / \mathrm{L}$. The concentrations found, besides being significant to public health, can potentially influence the functioning of the ecosystem. It is important to detach that COC and amphetamines (including metabolites as well) have potent pharmacological activities and their presence as complex mixtures in the environment may cause an adverse effect on aquatic organisms and in human health. However, unfortunately, there is no current regulation demanding the determination of the occurrence of these pollutants at the environment. This way, researches on the distribution pattern of these illicit drugs and their potentially harmful impact on our environment needs immediate attention and regulatory limits.
\end{abstract}

Keywords: Illicit drug; Drug consumption; Wastewater-Based Epidemiology; Detection

\section{Introduction}

Copy and paste here the content of the article. Copy and paste here the content of the article. Copy and paste here the The illicit drug is a worldwide problem with significant direct or indirect adverse effects on human health and social welfare [1]. They fall into the categories of opioids, cocaine, cannabis, amphetamine-type substances (ATSs) [2]. ATSs (largely amphetamine and methamphetamine) currently demand the most attention by law enforcement agencies [3,4] . Globally, ATSs and ecstasy are the second most commonly consumed illicit drugs after cannabis, and they are attractive to clandestine laboratory operators due to the easy availability of the precursor chemicals and their ease of manufacturing [5]. However, the use of ATSs continued to exceed that of heroin and cocaine combined [5], and millions of individuals are reported to be current users of ATS drugs. Human use of these psychoactive substances is virtually universal [4].

Related to the consumption of illicit drugs, according to the latest estimates provided by the United Nations Office on Drugs and Crime (UNODC), approximately 275 million people worldwide, which is roughly 5.6 percent of the global population aged 15-64 years, used drugs at least once during 2016 [6]. Some 31 million people who use drugs suffer from drug use disorders, meaning that their drug use is harmful to the point where they may need treatment. However, most importantly, one out of ten, in other words almost 27 million people worldwide are considered to be problem drug

* Corresponding author: Aldo Pacheco Ferreira

Copyright (C) 2020 Author(s) retain the copyright of this article. This article is published under the terms of the Creative Commons Attribution Liscense 4.0. 
users [6]. Yet, because of its numerous facets, it is an extremely complex phenomenon to understand and measure. Current knowledge about how drug use originates develops and affects, directly or indirectly, people's lives and societies is limited by the flaws of methods used to measure it. It is in this context that the analysis, in wastewater, of markers of drug use has seen the light.

Large amounts of illicit drugs are consumed, metabolized and eliminated from the human body in urinary and fecal excretions and the excreted parent compounds and metabolites are detectable in sewage [7]. Thus have been released into the environment during manufacturing, trafficking, and post-consumption, resulting in the wide detection of this kind of emerging compounds worldwide [8] due to their incomplete removal in the wastewater treatment plants (WWTP). On the other hand, these compounds may have potent pharmacological and biological activities and their presence in surface waters even at low concentrations, together with the residues of many therapeutic pharmaceuticals and other organic compounds, may lead to unexpected pharmacological interactions causing toxic effects to aquatic organisms. Also, they may cause a wide variety of environmental and health problems [9].

It is a matter of concern that in Brazil, around 59\% of the sewage produced is not treated and dumped in nature. Therefore, the contamination of source waters occurs, compromising the quality of drinking water concerning the presence of illegal substances and its major metabolites, which are only partially removed in drinking water treatment plants (DWTP). This contamination may pose a risk to humans, especially considering that $17 \%$ of Brazilian cities are not fully served by the water distribution network [10].

Analysis of illicit drugs in wastewater and surface water employing mass spectrometry and the occurrence of these compounds in environmental waters have initiated by Daughton [11] which projected them to estimate the global consumption of a community. Then, Zuccato et al. [12] published a new calculation method called "Wastewater-Based Epidemiology" (WBE) for obtaining local and real-time estimates of drug consumption. These authors described the presence of the illicit drug cocaine (COC) and its metabolite benzoylecgonine (BE) in wastewaters and surface waters to estimate collective cocaine usage. The ability of WBE to provide useful and timely information on temporal (daily, weekly, monthly, and annually) and spatial (within- and between-countries) variations in illicit drug consumption has been demonstrated [7,8,11-27]. Presented as an objective, evidence-based and non-invasive approach, it has seen great developments in the past decade. However, as with every approach trying to model a complex phenomenon, no matter how sophisticated, it will always only provide a partial description of it. Figure 1 is a schematic diagram of WBE procedures. If the average dose and abuse frequency of a particular drug is known, the number of drug abusers can also be estimated.
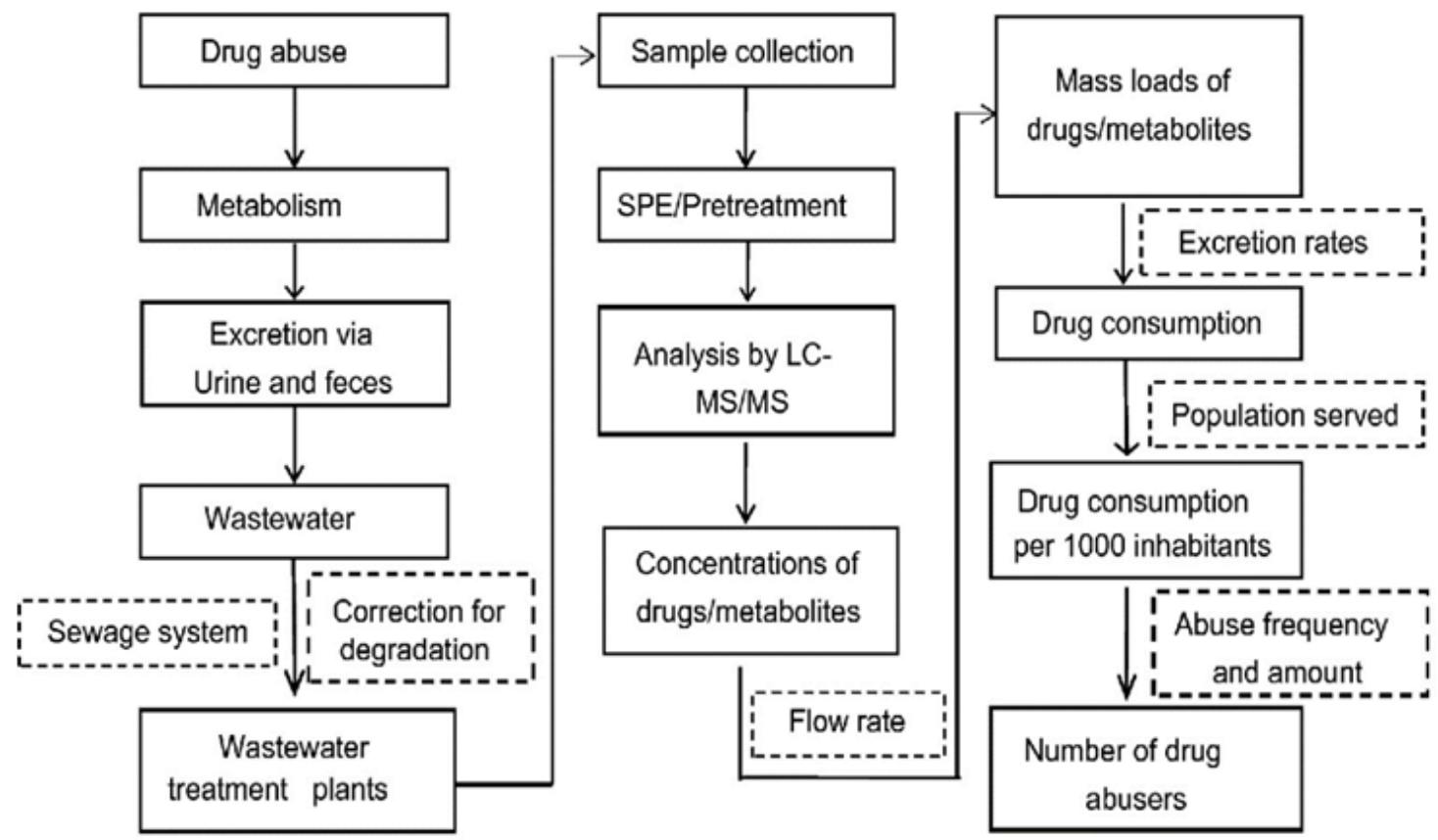

Figure 1 Schematic diagram of wastewater-based epidemiology [28] 


\subsection{Pharmacokinetics of illicit drugs}

The founding principle of WBE is related to the mechanism by which the consumption of illegal (and prescription) drugs can be detected, and eventually quantified, by measuring the occurrence of the parent compound or its metabolites in biological matrices [11-27]. Each xenobiotic will undergo specific pharmacokinetic and metabolization processes, which, depending on the substance, can last for longer periods and excretion products will thus be found in urine up to several days after administration [29]. As stated by Zuccato et al. [9] the ideal drug marker should be a major and exclusive excretion product of the drug under study that is stable in wastewater. Furthermore, it should also show limited inter- and intra-individual variability and should be excreted at similar rates regardless of the administration route and the dose.

Yet, none of the available drug residues fulfills all criteria. Firstly, pharmacokinetics and excretion rates depend on the individual, since body mass, diseases and other factors associated to the state of the consumer will influence the excretion rate for a given illicit drug [30]. Secondly, excretion rates depend on the administration route, as substances will have different bioavailability depending on how they enter the organism. This is an important aspect concerning pharmacokinetic studies available in the literature and commonly referenced in WBE approaches. Many of these trials have been carried out using administration routes, which do not reflect current user practices.

\subsubsection{Cannabis}

Cannabis (from the female plant of Cannabis sativa L; family Cannabidaceae) is worldwide the most widespread illicit drug. The major active compound in cannabis is $\Delta^{9}$-tetrahydrocannabinol (THC) and over 20 metabolites have been identified in human urine and feces. Excretion through the latter route has been shown to be the major pathway through which THC is eliminated from the human body [31]. It is worthy to detach that readily oxidizes to form THC-COOH, which is more stable. THC- $\mathrm{COOH}=11$-nor-9-carboxy- $\Delta^{9} 9$-tetrahydrocannabinol; OH-THC $=11$-Hydroxy- $\Delta^{9}$ tetrahydrocannabinol. The major metabolites encountered after the administration of cannabis and their respective excretion rates are reported in Table 1. In WBE studies, THC-COOH has generally been the target compound to monitor consumption of cannabis.

Table 1 Summary of the metabolites and their corresponding excretion rates measured in urine after administration of cannabis

\begin{tabular}{|c|c|c|c|c|}
\hline $\begin{array}{l}\text { Administered } \\
\text { compound }\end{array}$ & $\begin{array}{l}\text { Major } \\
\text { metabolites of } \\
\text { interest }\end{array}$ & $\begin{array}{l}\text { Urinary } \\
\text { excretion } \\
\text { Rate (\%) }\end{array}$ & $\begin{array}{l}\text { Administration } \\
\text { Route }\end{array}$ & Reference \\
\hline \multirow{2}{*}{ THC } & THC-COOH & $0.5-0.6$ & \multirow{2}{*}{ smoke } & \multirow{2}{*}{ [32] } \\
\hline & OH-THC & 2 & & \\
\hline
\end{tabular}

\subsubsection{Cocaine}

COC has been the target of most WBE studies published in the literature, mainly because of its widespread use [11-27]. After consumption, between 85 and $90 \%$ of the initial cocaine dose is excreted in urines in various forms within $24 \mathrm{~h}$ [33], as shown in Table 2. Liver carboxylases are responsible for the formation of BE, by the hydrolysis of the ester linkages of the parent compound. However, this reaction can also occur spontaneously at physiological pH [30]. COC, ecgonine methyl ester (EME) and BE can then be further modified to form minor metabolites such as ecgonine (ECG), norcocaine (NCOC) and cocaethylene (CE), the latter being excreted exclusively when cocaine and alcohol are coadministered [30].

Table 2 Summary of the metabolites and their corresponding excretion rates measured in urine after administration of cocaine by nasal insufflation

\begin{tabular}{llll}
\hline $\begin{array}{l}\text { Major metabolites of } \\
\text { interest }\end{array}$ & $\begin{array}{l}\text { Urinary excretion } \\
\text { Rate (\%) }\end{array}$ & $\begin{array}{l}\text { Administration } \\
\text { Route }\end{array}$ & References \\
\hline Cocaine & $1-15$ & & \\
Benzoylecgonine & $15-55$ & Nasal insufflation & {$[30,34,35]$} \\
Ecgonine methyl ester & $32-49$ & & \\
\hline
\end{tabular}




\subsubsection{Amphetamine-type stimulants}

Amphetamine-type stimulants (ATS) represent a class of compounds derived from phenethylamine to which a methyl group is linked to the $\alpha$ carbon. Among the various molecules, the most encountered ones are $( \pm)$-Amphetamine, $( \pm)$ Methamphetamine, ( \pm )-3,4-Methylenedioxymethamphetamine (MDMA), ( \pm )-3,4-Methylenedioxethylamphetamine (MDEA), ( \pm )-3,4-Methylenedioxyamphetamine (MDA) and Ephedrine. However, with the ever-growing number of new psychoactive substances appearing on the market every year [36], this group of compounds has seen an important increase in recent years. Synthesis of ATS in illegal laboratories tends to produce racemic mixtures since criminals do not possess the knowledge or the instrumentation to obtain enantiopure drugs. This is not the case for industrial of pharmaceutical productions where products generally contain only one enantiomer or determined proportion of each of them.

The metabolic process involved in the excretion of MDA, MDMA, MDEA and the other derivatives has not yet been studied extensively. In the particular case of MDMA, an important variability in excretion rates of the parent compound has been attributed to its nonlinear elimination, which increases as a function of the administered dose [37]. In some WBE studies, an excretion rate of $12-47 \%$ of the initial dose of MDMA after consumption [38]. Specific metabolites of MDMA (i.e., 4-hydroxy-3-methoxymethamphetamine (HMMA) and 4-hydroxy-3-methoxyamphetamine (HMA)) have been reported in the literature and can be used as markers of MDMA consumption in WBE studies [39]. Table 3 summarizes the metabolites and expected excretion rates after administration of the major ATS.

Table 3 Summary of the metabolites and their corresponding excretion rates measured in urine after administration of the major ATS

\begin{tabular}{lllll}
\hline $\begin{array}{l}\text { Administered } \\
\text { compound }\end{array}$ & $\begin{array}{l}\text { Major metabolites } \\
\text { of interest }\end{array}$ & $\begin{array}{l}\text { Urinary excretion } \\
\text { Rate (\%) }\end{array}$ & $\begin{array}{l}\text { Administration } \\
\text { Route }\end{array}$ & References \\
\hline Amphetamine & AM & $1-70$ & oral & {$[30]$} \\
Methamphetamine & METH & $2-76$ & oral & {$[30,35]$} \\
& AM & 7 & & \\
MDMA & MDMA & $12-47$ & oral & {$[40-44]$} \\
& HMMA & $11-49$ & & \\
\hline
\end{tabular}

The aim of this study was therefore to investigate the consumption patterns of illicit drugs (cocaine (COC), benzoylecgonine (BE, cocaine metabolite), amphetamine (AMP), methamphetamine (METH), and 11-nor-9-carboxytetrahydrocannabinol (THC-COOH, THC metabolite)) in Rio de Janeiro Municipality, Brazil. The specific goal of the study included a comparison of wastewater-based consumption estimates with the available epidemiological data.

\section{Material and methods}

\subsection{Reagents and materials}

Standards of BE, METH, AMP, THC, and THCCOOH were purchased at concentrations of $1 \mathrm{mg} / \mathrm{mL}$ in $1 \mathrm{~mL}$ methanol. Cocaine was acquired at $1 \mathrm{mg} / \mathrm{mL}$ in $1 \mathrm{~mL}$ acetonitrile. These standards were purchased from Sigma-Aldrich Brazil Ltda. (São Paulo, SP, Brazil). Deionized water was acquired from Milli-Q purification system (Merck Millipore, Goiânia, Brazil). Deuterated internal standards (cocaine-d3, BE-d3, cocaethylene-d3, amphetamine-d5, methamphetamine-d5, THC-d3 and THCCOOH-d3) were purchased at concentrations of $100 \mathrm{mg} / \mathrm{mL}$ in $1 \mathrm{~mL}$ methanol, and Cocaine-d3 was bought at $100 \mathrm{mg} / \mathrm{mL}$ in acetonitrile from Sigma-Aldrich Brazil Ltda. (São Paulo, SP, Brazil).

Liquid chromatography-mass spectrometry (LCMS) grade methanol, acetonitrile, isopropanol, and formic acid were purchased from Thermo Fisher Scientific (São Paulo, SP, Brazil). Hydrochloric acid (HCl) 36.5\%-38\% was from J.T. Baker Chemical Co. (Phillipsburg, NJ, USA). Reagent grade dichloromethane and ammonium hydroxide were purchased from Pharmco-Aaper (São Paulo, SP, Brazil). Nalgene ${ }^{\mathrm{TM}}$ certified wide-mouth amber high-density polyethylene (HDPE) $250 \mathrm{~mL}$ bottles, Whatman ${ }^{\mathrm{TM}}$ glass microfiber filters (outside diameter $4.7 \mathrm{~cm}$, particle retention $1.6 \mathrm{~mm}$, and thickness $0.26 \mathrm{~mm}$ ), EMD Millipore all-glass filter holder assembly (1000 mL), Sarstedt Inc $10 \mathrm{~mL}$ sc tubes $16 \mathrm{~mm}$ x $100 \mathrm{~mm}$, and $350 \mathrm{~mL}$ fused insert vials were acquired from Thermo Fisher Scientific. Oasis MCX cartridges $(150 \mathrm{mg} / 6 \mathrm{~mL})$ were 
produced by Waters (Waters Technologies do Brasil Ltda, Rio de Janeiro, Brazil) while Strata NH2 (200 mg/3 mL) cartridges, as well as HPLC columns used for the chromatographic separation (Synergi Polar; $4 \mu \mathrm{m}, 150 \mathrm{~mm} \times 3 \mathrm{~mm}$ and Kinetex PFP; $2.6 \mu \mathrm{m}, 100 \mathrm{~mm} \times 2.1 \mathrm{~mm}$ ), were manufactured by Phenomenex (São Paulo, SP, Brazil). Glass-fiber filters (GF/C) were delivered by Whatman (Bioquem, Belo Horizonte, Minas Gerais, Brazil).

Standards were diluted with LC-MS grade methanol at a ratio of 1:10 from the original ampoule to final concentrations of $100 \mathrm{mg} / \mathrm{mL}$. Ten milliliters of standard stock solution mixture was prepared at $1 \mathrm{mg} / \mathrm{mL}$ and a serial dilution utilizing a 1:10 dilution factor was performed until a final concentration of $0.001 \mathrm{mg} / \mathrm{mL}$ was obtained in methanol. Deuterated internal standards were diluted with LC-MS grade methanol at a ratio of 1:10 from the original ampoule to a final concentration of $10 \mathrm{mg} / \mathrm{mL}$. Ten milliliter of internal standard (IS) mixture was prepared at $0.1 \mathrm{mg} / \mathrm{mL}$ by 1:10 dilution in methanol. Standard and IS working solutions were stored in amber vials at $-20^{\circ} \mathrm{C}$. Working solutions were prepared by serial 1:10 dilutions in MilliQ water (Merck Millipore, Goiânia, Brazil), and were stored in amber vials at $4^{\circ} \mathrm{C}$.

\subsection{Wastewater samples collection}

For this study, wastewater samples were collected from WWTPs at four municipal boroughs of Rio de Janeiro Municipality. Pavuna WWTP has a capacity of $1097 \mathrm{~L} / \mathrm{s}$ and serves a population of 498,553 inhabitants, activated sludge system. Alegria WWTP has a capacity of $1529 \mathrm{~L} / \mathrm{s}$ and serves a population of 688,000 from four main sub-basins: Centro, Mangue, Catumbi, Alegria, Faria-Timbó and São Cristóvão, long-term activated sludge system. Penha WWTP has a capacity of $765 \mathrm{~L} / \mathrm{s}$ and serves a population of 344,051 inhabitants, activated sludge system. Barra Bonita WWTP has a capacity of $42 \mathrm{~L} / \mathrm{s}$ and serves a population of 18,923 inhabitants, activated sludge system (Figure 2).

The 24-h composite samples of untreated wastewaters were collected during between the spring period (September/2018), and early summer (December/2018) at the inlet of the municipal WWTPs. All composite samples were time-proportional (time-intervals: $30 \mathrm{~min}$ ). Each $24 \mathrm{~h}$-composite samples was obtained by collecting a $200 \mathrm{~mL}$ aliquot of the sanitary affluent using a time-proportional automatic sampler at 2-hour intervals [45]. Each $200 \mathrm{~mL}$ aliquot was transferred to a 5 - $\mathrm{L}$ plastic bottle and then stored in a refrigerator at $4^{\circ} \mathrm{C}$. At the end of the sampling, the cumulative sample was homogenized and 1-L of this sample was transferred to an amber flask (acidified on-site after sub-sampling) and transported under refrigeration to the laboratory [17]. The samples collected during the sampling campaign were frozen immediately after the collection and kept in the freezer $\left(-20^{\circ} \mathrm{C}\right)$ until analysis.

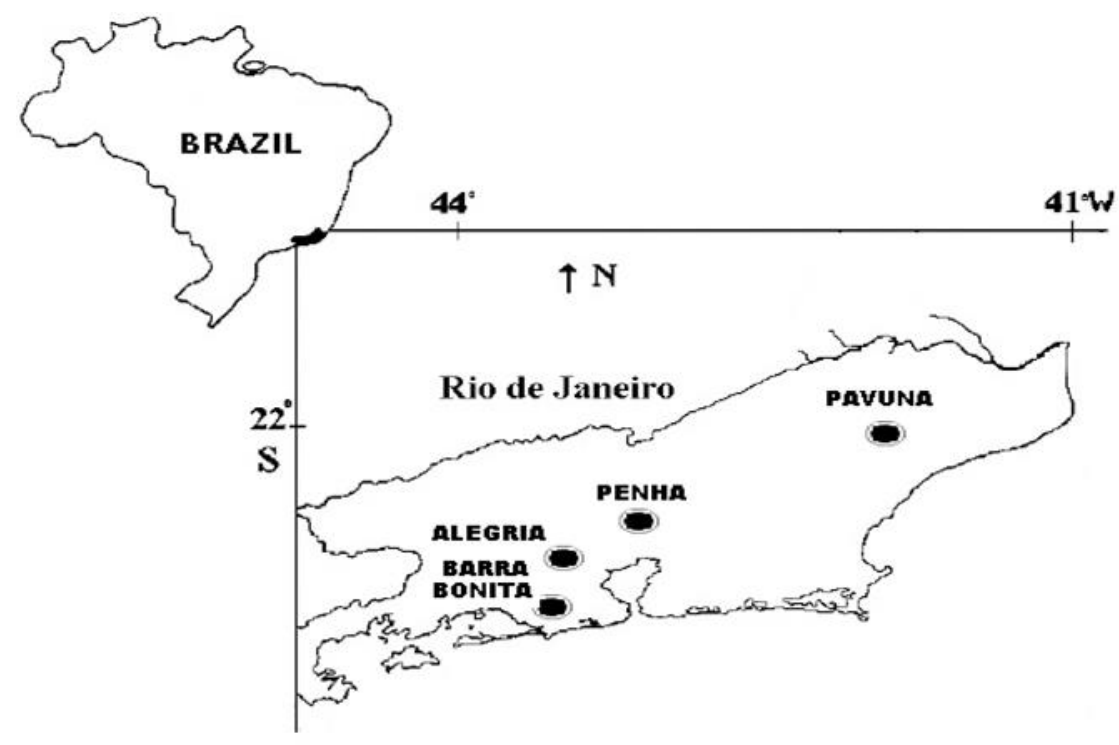

Figure 2 Map of Rio de Janeiro Municipality with indicated sampling locations

\subsection{Analytical methodology}

The sample preparation and instrumental analysis were performed according to Senta et al. [46]. Briefly, the wastewater samples $(125 \mathrm{~mL})$ were spiked with surrogate standards $(120 \mathrm{ng} / \mathrm{L})$ and filtered using $\mathrm{GF} / \mathrm{C}$ filters.

The Solid-phase extraction (SPE) method was performed with Oasis HLB Cartridges. Commercial HLB Oasis® cartridges $(6 \mathrm{~mL}, 500 \mathrm{mg})$ were obtained from Waters Corporation (Waters Technologies do Brasil Ltda, Rio de Janeiro, Brazil). 
The HLB cartridges were equilibrated with three $\mathrm{mL}$ of methanol (MeOH), four $\mathrm{mL}$ of acetonitrile (ACN) and five $\mathrm{mL}$ of ultrapure water. After percolation of the filtered samples $(1 \mathrm{~L})$, the cartridges were vacuum dried $(10 \mathrm{~mm} \mathrm{Hg})$ for $10 \mathrm{~min}$, and eluted with six mL of an ACN:MeOH, 60:40 ( $\left.\mathrm{v} \mathrm{v}^{-1}\right)$ solution, and evaporated to dryness under a nitrogen stream. The dry extract was dissolved in $1.0 \mathrm{~mL}$ of $0.1 \%$ aqueous formic acid: $\mathrm{ACN}, 90: 10\left(\mathrm{v} \mathrm{v}^{-1}\right)$ solution and transferred to vials for LC-MS/MS analysis.

\subsection{LC-MS/MS analysis}

The LC-MS/MS analysis was performed using a liquid chromatograph Agilent 1200 series, with a binary pump, connected to a 6410 triple quadrupole mass spectrometer equipped with electrospray ionization source (Agilent Technologies, Palo Alto, CA, USA) [10]. Separation used a Zorbax SB-C18 (30 $\mathrm{mm} \times 2.1 \mathrm{~mm}, 3.5 \mu \mathrm{m})$ reversed-phase HPLC column (Agilent Technologies, Palo Alto, CA - USA). Formic acid solutions $\left(0.1 \%, v^{-1}\right)$ (eluent A) and ACN (Eluent B) were used as mobile phase solvents. The following gradient program was performed: initial condition at $10 \%$ of eluent B kept for $0.5 \mathrm{~min}$, followed by a linear gradient reaching $80 \%$ of eluent B in $5 \mathrm{~min}$. This condition was kept for $2 \mathrm{~min}$, and then a 4 min linear gradient back to $10 \%$ of eluent $\mathrm{B}$. To equilibrate the column for the next run, the initial condition was held for $5 \mathrm{~min}$. The flow and the column temperature rate were held at $0.3 \mathrm{~mL} \mathrm{~min}^{-1}$ and $35^{\circ} \mathrm{C}$, and $10 \mu \mathrm{L}$ of each sample was injected into the LC-MS/MS system.

The electrospray source was operated in the positive polarity. High purity nitrogen was used as desolvation $\left(350^{\circ} \mathrm{C} ; 10\right.$ $\mathrm{L} \mathrm{min}^{-1}$ ), nebulizer and collision gas. Nebulizer pressure was kept at $30 \mathrm{psi}$ and the capillary voltage set at $2500 \mathrm{~V}$. The fragmentor was optimized at $120 \mathrm{~V}$ for all analytes, which were analyzed in multiple reaction monitoring (MRM) mode, recording the transitions between the precursor ion and the three most abundant product ions for each target analyte. The most intense transition was used as a quantifier ion (MRM1) and the others as a qualifier ion (MRM2). The identification of the analytes was confirmed by comparing the retention time and the MRM1/MRM2 ratio with the corresponding values of analytical standards measurements. The method accuracy was in the range from 83\% to $116 \%$ and extraction recovery between $60 \%$ and $94 \%$. The method quantification limits were between $0.1 \mathrm{and} 5 \mathrm{ng} / \mathrm{L}$.

\subsection{Daily loads and drug use estimate calculations}

The assessment of drug consumption was performed by applying the methodology proposed by Zuccato et al. [9]. The consumption of individual drugs (expressed as the number of average doses per 1000 inhabitants) was calculated by multiplying the population normalized representative average mass loads of selected drug biomarkers by the corresponding correction factors and by dividing with the corresponding average dose size.

Table 4 Characteristics of wastewater treatment plants (WWTPs) included in the study

\begin{tabular}{|c|c|c|c|c|}
\hline \multirow{2}{*}{ Data } & \multicolumn{4}{|c|}{ Wastewater treatment plants (WWTPs) } \\
\hline & Pavuna & Alegria & Penha & Barra Bonita \\
\hline Number of inhabitants & 498,553 & 695,050 & 397,200 & 22,555 \\
\hline $\begin{array}{l}\text { Number of treated drug consumers/1000 } \\
\text { inhabitants } \infty\end{array}$ & 2,23 & & & \\
\hline No. of inhabitants served by WWTP & 498,553 & 688,000 & 344,051 & 18,923 \\
\hline WW flow (L/s) & 1097 & 1529 & 765 & 44 \\
\hline
\end{tabular}

All screened analytes were considered as potential indicators of drug consumption over the course of the sampling campaign. The potential loss of metabolites from wastewater during sample extraction was corrected through labeled internal standards and the isotope dilution method. Narcotic mass loadings were calculated from analyte concentrations in raw wastewater (in units of ng/L) for daily wastewater flows using Eq. (1):

Mass Load $\left(\frac{\mathrm{mg}}{\mathrm{day}}\right)=$ Raw Concentration $\left(\frac{\mathrm{ng}}{\mathrm{L}}\right) *$ Flow $\left(\frac{\mathrm{L}}{\mathrm{d}}\right) *\left(\frac{1 \mathrm{mg}}{1,000,000 \mathrm{ng}}\right)$

Drug consumption estimates were obtained by normalizing the mass load of illicit drugs to the estimated contributing population and subsequently subjected to a correction factor, which accounts for metabolic excretion of the compounds [47-52]. The population normalized daily mass loads were obtained by dividing the representative average mass loads with the number of inhabitants (in thousands) served by the investigated WWTP. 
Apart from some exceptions, the correction factors used in the calculation of drug consumption were taken from the paper published by Zuccato et al. [9]. The estimation of cocaine consumption was made by using a later proposed correction factor of 3.6 [52], while the estimation of methadone consumption was performed by using recently proposed correction factor of 2.0 [50]. The consumption data were transformed into the number of average drug doses by applying the data on the size of a dose presented in Table 4 .

\subsection{Statistical Analysis}

Data analysis (counts, percentages, means) was performed with Excel software (Microsoft Office Excel 2016). All statistical analyses were performed using Origin 7.5. (OriginLab Corporation). Normal distribution was checked by Kolmogorov-Smirnov and Shapiro-Wilk tests for all variables. Statistical significant differences of the median were judged by one-way analysis of variance (ANOVA) and least significant differences calculations at a $5 \%$ significant level.

\section{Results and discussion}

The lack of previous data regarding the presence of illicit drugs in wastewater prompted this analysis of the presence of selected types of illegal drugs in wastewater from a number of WWTPs in Rio de Janeiro Municipality.

A total of 32 samples of untreated wastewater were analyzed during the study period. Samples were taken every month from September to December 2018, at the following intervals: September $(n=2)$, October $(n=2)$, November $(n=2)$ and December $(\mathrm{n}=2)$. Therefore, it was decided to analyze the occurrence of illegal drugs in wastewater. The obtained data provide the first more detailed information on the incidence of illicit drugs in wastewaters. The samples were taken and subsequently analyzed by LC-MS/MS. The incidences of the most commonly used drugs, methamphetamine; cocaine; the main cocaine metabolite in wastewater, BE, AMP, METH, THCCOOH were compared with the results reported in other studies.

The concentration of cannabis in wastewater from the monitored sites was calculated based on the concentration of the metabolite THC-COOH. The concentrations of METH, AMP, COC, and BE were calculated directly from the measured values of the parent drugs in the wastewater.

Based on the concentrations of drugs in the wastewater and the corresponding daily flow rate of wastewater in a treatment plant, the daily quantities of the drugs in the wastewater were obtained.

These values were specifically related to 1000 inhabitants connected to the WWTP. The obtained results represent the specific loads of the drugs in wastewater related to the population on a given day (mg/day/1000 inhabitants). Thus, drug consumption values in selected cities correlate with the specific loads of the drugs in wastewater.

The consumption of illicit drugs in society is currently one of the biggest social problems and is also emerging as a possible environmental problem. The presence of illicit drugs in environmental matrices, mainly surface water, arises as a matter associated with the contribution of effluents from WWTPs and, in countries with a low rate of wastewater treatment such as Brazil, it is associated with the contribution of crude sewage as important pollutant. Therefore, due to the complexity of the matrices and the importance of the determination of these substances, the development of reliable analytical methods is a real necessity.

An important indicator related to the fight against illicit drugs is the amount of substance circulating or consumed in a city, state or country. At present, this data is obtained indirectly through extrapolations from socio-epidemiological investigations [17]. Such investigations use data on drug seizures, medical hospitalization records, population investigations and interviews with users. However, these methods are obtained in a very onerous, slow manner, and do not provide real-time knowledge about the consumption and/or trafficking of narcotics in a region [14].

\subsection{The occurrence of illicit drugs and metabolites in wastewaters}

The concentration of illicit drugs in WWTPs from the monitored sites is presented in Table 5.

Concentrations of COC and its main metabolite BE ranged from 201.3 to $2751.5 \mathrm{ng} / \mathrm{L}$ and from 630.7 to $5849.2 \mathrm{ng} / \mathrm{L}$, respectively. The highest specific loads of COC used were found in Alegria ( $91.7 \mathrm{mg} /$ day $/ 1000$ inhabitants), followed by Pavuna (68.4 mg/day/1000 inhabitants), Barra Bonita (34.6 mg/day/1000 inhabitants), and Penha (11 mg/day/1000 inhabitants). 
Amphetamine-like stimulants (AMP and METH) ranged from 1.7 to $110.0 \mathrm{ng} / \mathrm{L}$ for AMP. The highest mean specific load of AMP in wastewater during the monitored days was found also at the Alegria WWTP (19 mg/day/1000 inhabitants), and the lowest value was measured in Barra Bonita WWTP $(1.8 \mathrm{mg} /$ day/1000 inhabitants). The concentrations of METH in wastewater ranged from $55.3 \mathrm{ng} / \mathrm{L}$ (Barra Bonita) to $477.4 \mathrm{ng} / \mathrm{L}$ (Pavuna). The highest concentrations were typically found in areas with known drug problems or with inhabitants of low socio-economic backgrounds, such as some areas in Rio de Janeiro Municipality, like Pavuna. In this study, the Pavuna WWTP had the highest mean specific load of METH in the wastewater $(109.6 \mathrm{mg} /$ day $/ 1000$ inhabitants), followed by Alegria $(92.1 \mathrm{mg} /$ day/1000 inhabitants), Penha (56.3 mg/day/1000 inhabitants) and Barra Bonita ( $8.3 \mathrm{mg} /$ day/1000 inhabitants).

The concentration of THC-COOH ranged from 188.8 to $940.2 \mathrm{ng} / \mathrm{L}$. The loads for this drug were $(37.7 \mathrm{mg} /$ day $/ 1000$ inhabitants) in Alegria, (32.3 mg/day/1000 inhabitants) in Pavuna, $(28.5 \mathrm{mg} /$ day/1000 inhabitants) in Penha, and $(22.2 \mathrm{mg} /$ day/1000 inhabitants) in Barra Bonita, indicating that cannabis is used in many large areas at the studied region.

The concentration of illicit drugs and metabolites (ng/L) in the WWTPs from the monitored sites (1-Alegria, 2-Penha, 3-Pavuna, and 4-Barra Bonita) and estimated mean consumption is in good agreement with published results for some other studies $[3,4,7,8,15,16,27,28,41-43]$.

Chemical analysis of wastewater performed in the present study has revealed the presence of residues of illicit drugs in the influents of the WWTPs analyzed. Samples of wastewater generated by more than 1.6 million inhabitants of four areas were analyzed for illicit drugs including METH, COC, BE, AMP, and TCHCOOH. The most commonly used hard drug was cocaine. The expected would be cannabis due to be cheap or even free and often produced by groups of end-users [53].

Residues of illicit drugs have become widespread surface water contaminants in populated areas. Like for therapeutic pharmaceuticals, this contamination appears to be common, consumers being the major source. After consumption, these substances can be excreted as the parent compound and/or metabolites in urine and faeces. Several widely used drugs are excreted unchanged or as active metabolites in high percentages after consumption and continuously discharged into domestic wastewaters. Several substances can, therefore, reach WWTPs in substantial amounts and, if they escape degradation, can be released into surface water, what is worse. 
Table 5 Concentration of illicit drugs and metabolites (ng/L in WWTPs from the monitored sites (1-Alegria, 2-Penha, 3-Pavuna and 4- Barra Bonita) and the estimate of medium consumption. Municipality of Rio de Janeiro, 2018.

\begin{tabular}{|c|c|c|c|c|c|c|c|c|c|}
\hline \multirow{2}{*}{$\begin{array}{l}\text { Drugs and } \\
\text { Metabolites }\end{array}$} & \multicolumn{4}{|c|}{ Concentration (ng/L) } & \multicolumn{4}{|c|}{$\begin{array}{l}\text { Consumption of drugs } \\
\text { (mg/day/1000 inhabitants between } 15 \text { and } 64 \text { years old) }\end{array}$} & \multirow[t]{2}{*}{ Chemical Group } \\
\hline & WWTP-1 & WWTP-2 & WWTP-3 & WWTP-4 & WWTP-1 & WWTP-2 & WWTP-3 & WWTP-4 & \\
\hline AMP & 88.8 & 34.3 & 110 & 21.7 & \multirow{2}{*}{92.1} & \multirow{2}{*}{56.3} & \multirow{2}{*}{109.6} & \multirow{2}{*}{8.3} & \multirow{2}{*}{$\begin{array}{l}\text { Amphetamine-like } \\
\text { stimulants }\end{array}$} \\
\hline METH & 345.2 & 212.6 & 477.4 & 55.3 & & & & & \\
\hline THC-COOH & 940,2 & 437.4 & 188.8 & 662.3 & 37.7 & 28.5 & 32.3 & 22.2 & Cannabis \\
\hline $\mathrm{BE}$ & 5849.2 & 630.7 & 2580.9 & 1285.1 & \multirow{2}{*}{91.7} & \multirow{2}{*}{11} & \multirow{2}{*}{68.4} & \multirow{2}{*}{34.6} & \multirow{2}{*}{ Cocaine } \\
\hline $\mathrm{COC}$ & 2751.5 & 201.3 & 1732.2 & 823.8 & & & & & \\
\hline
\end{tabular}




\section{Conclusion}

This study represents the first detailed analysis of drug consumption in Rio de Janeiro Municipality based on wastewater analysis. The analysis of sewage waters of the 4 main WWTPs that treat the wastewaters of Rio de Janeiro Municipality provides valuable information about illicit drugs that are used in this area.

The discoveries support some of the existing hypotheses about regional features, but also provide additional evidence about geographical particularities. Understanding illicit drug consumption remains a difficult task; however, the results of this research illustrate how the combination of different and complementary data sources allows for obtaining a more accurate picture of the situation. The information can be used to monitor changes in drug use, identify potential dangers, promote the setup of targeted surveys, prevention campaigns and/or police actions), understand the structure of drug markets and guide future drug policies. Although wastewater analysis does not provide direct information about users, its ability to provide close to real-time data and its potential integration in existing monitoring programs make it a valuable tool to help under-standing illicit drug consumption.

Accurate and timely information about the scale and dynamics of drug consumption is important for assessing the needs of law enforcement and public health services in a community. Careful analysis of sewage samples can provide valuable information on the scale of drug consumption, but with a comprehensive investigation into the kinetics of drug-flow, this technique can also provide valuable support in identifying trends in drug use patterns. Such information can add additional quantitative weight to the findings of sociological and general population surveys.

\section{Compliance with ethical standards}

\section{Acknowledgments}

This study was financially supported by National Council for Scientific and Technological Development (CNPq). I also thank the Public Entity of Wastewater Treatment at Rio de Janeiro and all the personal of the WWTPs are acknowledged for their help with the sampling. The laboratory support was fundamental for the analyses (Fiocruz, Puc-RJ, UFRJ).

\section{Disclosure of conflict of interest}

The author declares no conflicts of interest.

\section{Statement of ethical approval}

The present work had the approval of the Research Ethics Committee of the Sergio Arouca National School of Public Health (ENSP/FIOCRUZ).

\section{References}

[1] Schulte MT and Hser YI. (2014). Substance Use and Associated Health Conditions throughout the Lifespan. Public health reviews, 35(2),

[2] Hall W, Degenhardt L and Sindicich N. (2008). Illicit drug use and the burden of disease. In: Heggenhougen K., Quah S., editors. International encyclopedia of public health. Elsevier, 523-530.

[3] Logan BK. (2001). Amphetamines: an update on forensic issues. J Anal Toxicol, 25, 400-404.

[4] Griffiths P, Meacham M and McKetin R. (2008). Illicit drug trends globally. In: Heggenhougen K., Quah S., editors. International encyclopedia of public health. Elsevier, 515-523.

[5] UNODC. (2014). United Nations Office on Drugs and Crime. Amphetamines and Ecstasy: Global ATS Assessment. United Nations Publication.

[6] United Nations Office on Drugs and Crime. World Drug Report. (2018).

[7] Nefau T, Karolak S, Castillo L, Boireau V and Levi Y. (2013). Presence of illicit drugs and metabolites in influents and effluents of 25 sewage water treatment plants and map of drug consumption in France. Sci Total Environ, 461-462, 712-722.

[8] Hu P, Guo C, Zhang Y, Lv J, Zhang Y and Xu J. (2019). Occurrence, distribution and risk assessment of abused drugs and their metabolites in a typical urban river in north China. Front. Environ. Sci. Eng, 13(4), 56-67. 
[9] Zuccato E, Castiglioni S, Bagnati R, Chiabrando C, Grassi P and Fanelli R. (2008). Illicit drugs, a novel group of environmental contaminants. Water Res., 42, 961-968.

[10] Campestrini I and Jardim WF. (2017). Occurrence of cocaine and benzoylecgonine in drinking and source water in the São Paulo State region, Brazil. Sci Total Environ., 576, 374-380.

[11] Daughton CG. (2001). Illicit Drugs in Municipal sewage: Proposed new non-intrusive tool to heighten public awareness of societal use of illicit/abused drugs and their potential for ecological consequences. In: Daughton C.G., Jones-Lepp T., editors. Pharmaceuticals and personal care products in the environment: scientific and regulatory issues. Symposium Series. Washington, D.C.: American Chemical Society, 348-364.

[12] Zuccato E, Chiabrando C, Castiglioni S, Calamari D, Bagnati R, Schiarea S and Fanelli R. (2005). Cocaine in surface waters: a new evidence-based tool to monitor community drug abuse. Environ Health, 7, 1-7.

[13] Gheorghe A, van Nuijs A, Pecceu B, Bervoets L, Jorens PG, Blust R, Neels H and Covaci A. (2008). Analysis of cocaine and its principal metabolites in waste and surface water using solid-phase extraction and liquid chromatographyion trap tandem mass spectrometry. Anal Bioanal Chem., 391, 1309-1319.

[14] Postigo C, López de Alda MJ and Barceló D. (2009). Drugs of abuse and their metabolites in the Ebro River basin: occurrence in sewage and surface water, sewage treatment plants removal efficiency, and collective drug usage estimation. Environ Int., 36, 75-84.

[15] Terzic S, Senta I and Ahel M. (2010). Illicit drugs in wastewater of the city of Zagreb (Croatia) - estimation of drug abuse in a transition country. Environ Pollut., 158, 2686-2693.

[16] Harman C, Reid M and Thomas KV. (2011). In situ calibration of a passive sampling device for selected illicit drugs and their metabolites in wastewater, and subsequent year-long assessment of community drug usage. Environ Sci Technol., 45, 5676-5682.

[17] van Nuijs ALN, Mougel JF, Tarcomnicu I, Bervoets L, Blust R, Jorens PG, Neels H and Covaci A. (2011). Sewage epidemiology- a real-time approach to estimate the consumption of illicit drugs in Brussels, Belgium. Environ Int., 37, 612-621.

[18] Maldaner AO, Schmidt LL, Locatelli MAF, Jardim WF, Sodré FF, Almeida FV, Pereira CEB and Silva CM. (2012). Estimating Cocaine Consumption in the Brazilian Federal District (FD) by Sewage Analysis. J. Braz. Chem. Soc., 23(5), 861-867.

[19] Mackul'ak T, Skubák J, Grabic R, Ryba J, Birošová L, Fedorova G, Spalková V and Bodík I. (2014). National study of illicit drug use in Slovakia based on wastewater analysis. Sci Total Environ, 494-495, 158-165.

[20] Ort C, Eppler JM, Scheidegger A, Rieckermann J, Kinzig M and Sörgel F. (2014). Challenges of surveying wastewater drug loads of small populations and generalizable aspects on optimizing monitoring design. Addiction, 109, 472-481.

[21] Ostman M, Fick J, Näsström E and Lindberg RH. (2014). A snapshot of illicit drug use in Sweden acquired through sewage water analysis. Sci Total Environ, 472, 862-871.

[22] Been F, Bijlsma L, Benaglia L, Berset JD, Botero-Coy AM, Castiglioni S, Kraus L, Zobel F, Schaub MP, Bücheli A, Hernández F, Delémont O, Esseiva P and Ort C. (2016). Assessing geographical differences in illicit drug consumption - A comparison of results from epidemiological and wastewater data in Germany and Switzerland. Drug Alcohol Depend, 161, 189-199.

[23] Kankaanpää A, Ariniemi K, Heinonen M, Kuoppasalmi K and Gunnar T. (2016). Current trends in Finnish drug abuse: Wastewater based epidemiology combined with other national indicators. Sci Total Environ, 568, 864874.

[24] Krizman I, Senta I, Ahel M and Terzic S. (2016). Wastewater-based assessment of regional and temporal consumption patterns of illicit drugs and therapeutic opioids in Croatia. Sci Total Environ, 566-567, 454-462.

[25] Lai FY, O'Brien JW, Thai PK, Hall W, Chan G, Bruno R, Ort C, Prichard J, Carter S, Anuj S, Kirkbride KP, Gartner C, Humphries M and Mueller JF. (2016). Cocaine, MDMA and methamphetamine residues in wastewater: Consumption trends (2009-2015) in South East Queensland, Australia. Sci Total Environ, 568, 803-809.

[26] Zuccato E, Castiglioni S, Senta I, Borsotti A, Genetti B, Andreotti A, Pieretti G and Serpelloni G. (2016). Population surveys compared with wastewater analysis for monitoring illicit drug consumption in Italy in 2010-2014. Drug Alcohol Depend, 161, 178-188. 
[27] Mastroianni N, López-García E, Postigo C, Barceló D and López de Alda M. (2017). Five-year monitoring of 19 illicit and legal substances of abuse at the inlet of a wastewater treatment plant in Barcelona (NE Spain) and estimation of drug consumption patterns and trends. Sci Total Environ, 609, 916-926.

[28] Feng LZ, Zhang W and Li XQ. (2018). Monitoring of regional drug abuse through wastewater-based epidemiology - A critical review. Science China Earth Sciences, 61, 239-255.

[29] The Merck Manual - Second home edition. (2004). Section 2. Drugs, Chapter 11, Drug administration and kinetics.

[30] Jenkins AJ. (2007). Pharmacokinetics: drug absorption, distribution, and elimination. In: Karch S.B., editor. Drug abuse handbook. Boca Raton: CRC Press, 167.

[31] Pertwee RG. (2005). Pharmacological actions of cannabinoids. Handb Exp Pharmacol, 168, 1-51.

[32] Huestis MA. (2007). Human cannabinoid pharmacokinetics. Chem Biodivers, 4(8), 1770-804.

[33] Jatlow P. (1988). Cocaine: Analysis, pharmacokinetics, and metabolic disposition. Yale J Biol. Med, 61, 105-113.

[34] Jufer RA, Wstadik A, Walsh SL, Levine BS and Cone EJ. (2000). Elimination of cocaine and metabolites in plasma, saliva, and urine following repeated oral administration to human volunteers. J Anal Toxicol, 24, 467-477.

[35] Baselt RC and Cravey RH. (2014). Disposition of toxic drugs and chemicals in man. 10 $0^{\text {th }}$ Edition. Foster City, California: Biomedical Publications, 76.

[36] Evans-Brown M, Gallegos A, Francis W, Christie R, Cunningham A, Sekula J, Almeida A and Sedefov R. (2015). New psychoactive substances in Europe an update from the EU Early Warning System. Luxembourg: Publications Office.

[37] Mueller M, Peters FT, Huestis MA, Ricaurte GA and Maurer HH. (2009). Simultaneous liquid chromatographicelectrospray ionization mass spectrometric quantification of 3,4-methylenedioxymethamphetamine (MDMA, Ecstasy) and its metabolites 3,4-dihydroxymethamphetamine, 4-hydroxy-3-methoxymethamphetamine and 3,4methylenedioxyamphetamine in squirrel monkey and human plasma after acidic conjugate cleavage. Forensic Sci Int., 184, 64-68.

[38] Khan U and Nicell JA. (2011). Refined sewer epidemiology mass balances and their application to heroin, cocaine and ecstasy. Environ Int., 37, 1236-1252.

[39] Been F, Rossi L, Ort C, Rudaz S, Delémont O and Esseiva P. (2014). Population normalization with ammonium in wastewater-based epidemiology: Application to illicit drug monitoring. Environ Sci Technol., 48(14), 8162-8169.

[40] De La Torre R, Farré M, Ortuño J, Mas M, Brenneisen R, Roset PN, Segura J and Camí J. (2000). Non-linear pharmacokinetics of MDMA (ecstasy) in humans. Br J Clin Pharmacol, 49, 104-109.

[41] Segura M, Ortuño J, Farré M, McLure JA, Pujadas M, Pizarro N, Llebaria A, Joglar J, Roset PN, Segura J and de La Torre R. (2001). 3,4-Dihydroxymethamphetamine (HHMA). A major in vivo 3, 4methylenedioxymethamphetamine (MDMA) Metabolite in humans. Chem Res Toxicol, 14(9), 1203-1208.

[42] Ferreira AP. (2019). Illicit drugs in Wastewater Treatment Plants. A case study: Rio de Janeiro, Brazil. The Journal of Chemical Health Risks, 9, 191-202.

[43] Ferreira AP. (2019). Drugs of abuse and metabolites in urban wastewater: A case study, Rio de Janeiro Municipality, Brazil. World Journal of Research and Review, 9, 14-19.

[44] Pizarro N, Ortuño J, Farré M, Hernández-López C, Pujadas M, Llebaria A, Joglar J, Roset PN, Mas M, Segura J, Camí J and de la Torre R. (2002). Determination of MDMA and its metabolites in blood and urine by gas chromatography-mass spectrometry and analysis of enantiomers by capillary electrophoresis. J Anal Toxicol, 26(3), 157-165.

[45] Krizman I, Senta I, Ahel M and Terzic S. (2016). Wastewater-based assessment of regional and temporal consumption patterns of illicit drugs and therapeutic opioids in Croatia. Sci Total Environ, 566-567, 454-462.

[46] Senta I, Krizman I, Ahel M and Terzić S. (2013). Integrated procedure for multiresidue analysis of dissolved and particulate drugs in municipal wastewater by liquid chromatography-tandem mass spectrometry. Anal. Bioanal. Chem, 405, 3255-3268.

[47] Terzic S, Senta I and Ahel M. (2010). Illicit drugs in wastewater of the city of Zagreb (Croatia) - Estimation of drug abuse in a transition country. Environ. Pollut, 158, 2686-2693. 
[48] Baker DR and Kasprzyk-Hordern B. (2011). Multi-residue analysis of drugs of abuse in wastewater and surface water by solid-phase extraction and liquid chromatography-positive electrospray ionisation tandem mass spectrometry. J. Chromatogr. A, 1218(12), 1620-1631.

[49] Postigo C, López de Alda MJ and Barceló D. (2011). Evaluation of drugs of abuse use and trends in a prison through wastewater analysis, Environ. Int, 37, 49-55.

[50] Thai PK, Lai FY, Bruno R, van Dyken E, Hall W, O’Brien J, Prichard J and Mueller JF. (2016). Refining the excretion factors of methadone and codeine for wastewater analysis-combining data from pharmacokinetic and wastewater studies. Environ. Int, 94, 307-314.

[51] Gracia-Lor E, Zuccato E and Castiglioni S. (2016). Refining correction factors for back-calculation of illicit drug use, Sci. Total Environ, 573, 1648-1659.

[52] Castiglioni S, Bijlsma L, Covaci A, Emke E, Hernández F, Reid M, Ort C, Thomas KV, van Nuijs AL, de Voogt P and Zuccato E. (2013). Evaluation of uncertainties associated with the determination of community drug use through the measurement of sewage drug biomarkers. Environ. Sci. Technol, 47, 1452-1460.

[53] Ferreira AP. (2019). Estimaciones del consumo de drogas ilícitas derivadas del análisis de aguas residuales: Una revisión crítica. Rev Univ Ind Santander Salud, 51(1), 69-80.

\section{How to cite this article}

Ferreira AP. (2020). Illicit drugs in wastewater treatment plants utilization of wastewater-based epidemiology in a Brazilian regional city. World Journal of Advanced Research and Reviews, 6(1), 06-18. 